\title{
Modelling micropollutant fate in sewer systems - A new systematic approach to support conceptual model construction based on in-sewer hydraulic retention time
}

Delli Compagni, Riccardo; Polesel, Fabio; von Borries, Kerstin J.F.; Zhang, Zhen; Turolla, Andrea; Antonelli, Manuela; Vezzaro, Luca

Published in:

Journal of Environmental Management

Link to article, DOI:

10.1016/j.jenvman.2019.05.139

Publication date:

2019

Document Version

Peer reviewed version

Link back to DTU Orbit

Citation $(A P A)$ :

Delli Compagni, R., Polesel, F., von Borries, K. J. F., Zhang, Z., Turolla, A., Antonelli, M., \& Vezzaro, L. (2019). Modelling micropollutant fate in sewer systems - A new systematic approach to support conceptual model construction based on in-sewer hydraulic retention time. Journal of Environmental Management, 246, 141-149. https://doi.org/10.1016/j.jenvman.2019.05.139

\section{General rights}

Copyright and moral rights for the publications made accessible in the public portal are retained by the authors and/or other copyright owners and it is a condition of accessing publications that users recognise and abide by the legal requirements associated with these rights.

- Users may download and print one copy of any publication from the public portal for the purpose of private study or research.

- You may not further distribute the material or use it for any profit-making activity or commercial gain

- You may freely distribute the URL identifying the publication in the public portal 
$1 \quad$ Modelling micropollutant fate in sewer systems - A new systematic

2 approach to support conceptual model construction based on in-sewer

\section{hydraulic retention time}

5 Riccardo Delli Compagni ${ }^{1}$, Fabio Polesel $^{2,3}$, Kerstin J.F. von Borries ${ }^{2}$, Zhen Zhang ${ }^{2}$, Andrea

6 Turolla $^{1}$, Manuela Antonelli ${ }^{1 *}$ and Luca Vezzaro ${ }^{2 *}$

7

$8 \quad{ }^{1}$ Department of Civil and Environment Engineering (DICA), Politecnico di Milano, Piazza

9 Leonardo da Vinci 32, 20129 Milan, Italy

$10{ }^{2}$ DTU Environment, Technical University of Denmark, Bygningstorvet, Building 115, 2800

11 Kongens Lyngby, Denmark

$12{ }^{3}$ DHI A/S, Agern Allé, 2970 Hørsholm, Denmark

13

14

$15 *$ Corresponding author: manuela.antonelli@polimi.it

16 Co-corresponding author: luve@env.dtu.dk 
Abstract

19 Conceptual sewer models are useful tools to assess the fate of micropollutants (MPs) in integrated wastewater systems. However, the definition of their model structure is highly subjective, and obtaining a realistic simulation of the in-sewer hydraulic retention time $(H R T)$ is a major challenge without detailed hydrodynamic information or with limited measurements from the sewer network. This study presents an objective approach for defining the structure of conceptual sewer models in view of modelling MP fate in large urban catchments. The proposed approach relies on GIS-based information and a Gaussian mixture model to identify the model optimal structure, providing a multi-catchment conceptual model that accounts for $H R T$ variability across urban catchment. This approach was tested in a catchment located in a highly urbanized Italian city and it was compared against a traditional single-catchment conceptual model (using a single average $H R T$ ) for the fate assessment of reactive MPs. Results showed that the multi-catchment model allows for a successful simulation of dry weather flow patterns and for an improved simulation of MP fate compared to the classical single-catchment model. Specifically, results suggested that a multi-catchment model should be preferred for (i) degradable MPs with half-life lower than the average $H R T$ of the catchment and (ii) MPs undergoing formation from other compounds (e.g. human metabolites); or (iii) assessing MP loads entering the wastewater treatment plant from point sources, depending on their location in the catchment. Overall, the proposed approach is expected to ease the building of conceptual sewer models, allowing to properly account for $H R T$ distribution and consequently improving MP fate estimation.

Keywords: geographical information system, cluster analysis, sewer system modelling, wastewater-based epidemiology, emerging contaminants 


\section{Introduction}

43 Organic micropollutants (MPs) have been recognized as a concern for the environment and human

44 health due to the detrimental effects (e.g. toxicity, estrogenicity) they can pose even at low 45 concentrations (ng L ${ }^{-1}$ to $\mu \mathrm{g} \mathrm{L}^{-1}$ ) (Galus et al., 2013; Fent et al., 2006; Daughton and Ternes, 1999). 46 Several MPs (e.g. pharmaceuticals and personal care products) enter the water cycle through 47 wastewater discharges flowing along sewer systems to wastewater treatment plants (WWTPs), 48 where they are not entirely removed and consequently discharged into environmental recipients 49 (Petrie et al., 2015). In sewer systems, MPs can undergo degradation (biotic and abiotic), adsorption and retransformation - from other excreted metabolites (Bahlmann et al., 2014), remobilisation of sewer deposit (Launay et al., 2016), abiotic formation from other MPs (Sengeløv et al., 2003). The importance of these processes depends on the MP properties, environmental and hydraulic conditions (D’Ascenzo et al., 2003; Gomes et al., 2009; Plósz et al., 2012; Thai et al., 2014; Ramin et al., 2016; McCall et al., 2016; Menzies et al., 2017). Combining the abovementioned processes with the hydrodynamics of the sewer itself is a challenging modelling task. Nevertheless, MP fate models can be highly beneficial for (i) providing high-frequency input data to assess performances of WWTP models (i.e. to assess MP discharge into the environment) when full-scale measurements are scarce (e.g. Snip et al., 2014); (ii) evaluating possible mitigation strategies within the urban drainage system taking into account interactions with the WWTP system (e.g. Eriksson et al., 2011); and (iii) back-calculating consumption of chemicals in upstream catchments using wastewater-based epidemiology approaches while considering in-sewer losses (e.g. McCall et al., 2017).

63 In sewer systems, water transport is usually modelled by using distributed hydrodynamic or conceptual models (Obropta and Kardos, 2007; Zoppou, 2001). Hydrodynamic models are computationally demanding and require detailed information about the network (number of pipes, slopes, diameters, etc.) to explicitly describe the hydraulic conditions (e.g. water level, flow velocity, etc.) in each part of the system. On the other hand, conceptual models lump parts of the 
system into simple units, while flow routing is described by using continuously stirred tank reactors

69 (CSTRs) in series (Saagi et al., 2016). These models use general information such as the average hydraulic residence time $(H R T)$ to describe water dynamics at specific points of the system (e.g. the sewer outlet, overflow structure). The loss of details is balanced by the increase of computational speed, making conceptual models ideal for simulating water quality, both for traditional water quality indicators (Flores-Alsina et al., 2014; Martin and Vanrolleghem, 2014) and MPs (De Keyser et al., 2010; Snip et al., 2016; Mannina et al., 2017). Although alternative approaches have been also tested to simulate the stochastic behaviour of specific MP sources (Ort et al., 2005; Pouzol et al., 2018), conceptual models are often applied in a deterministic manner (i.e. MP sources are modelled as deterministic).

The realistic description of in-sewer $H R T$ represents a major challenge for the development of in-sewer MP processes and their overall attenuation, and it should therefore be carefully considered during model construction (Jelic et al., 2015; Polesel et al., 2016; Ramin et al., 2016, McCall et al., 2017; Li et al., 2018). Typically, one of the first steps during model construction consists of subdividing the urban catchment into smaller sub-catchments in a heuristic or empirical manner, where HRTs are defined based on the available information of the area (e.g. geographical maps, topography, distances). However, this step is highly subjective and requires several trial-and-error iterations. To make this step objective, automatic algorithms have been proposed for hydrological models (Davidsen et al., 2017; Wolfs et al., 2013), while tools supporting the building of conceptual models focusing on water quality are still missing. Alternative approaches have been developed to define $H R T$ as a probability density distribution, which was derived using road network as proxy variable for sewer network (Kapo et al., 2017) or by running complex hydrodynamic models

91 (McCall et al., 2017). To date, however, an automated procedure for constructing a conceptual model is still lacking. 
93 This study aimed at developing a new, systematic and fast approach to support the construction of

94 conceptual models for predicting in-sewer MP fate in large urban catchments. The method relies on

95 GIS information (e.g. consumer locations and sewer network), quantitative data (e.g. water

96 consumption and WWTP inflow data) and advanced statistical techniques (cluster analysis) in order

97 to cluster areas of the urban catchment based on similar $H R T$. As a result, a multi-catchment 98 conceptual model (i.e. with a discrete $H R T$ distribution) is obtained. The approach was tested for a 99 large urban catchment and its performance was compared against a traditional single-catchment 100 model (i.e. one $H R T$ ) for three scenarios: (i) MP undergoing biodegradation; (ii) MP undergoing 101 biodegradation and retransformation; (iii) MP emissions from a point source at different locations in 102 the catchment, i.e. with different distance and transport time to the receiving WWTP. 


\section{Materials and methods}

\subsection{Case study}

106 The modelling approach was developed for a large urban catchment in Northern Italy (total area of $10769 \mathrm{~km}^{2}$ with approximately 1.250 .000 inhabitants with a negligible industrial contribution. The 108 catchment is relatively flat (maximum elevation change of 40 meters over about $10 \mathrm{~km}$ ) and all the 109 wastewater flow is gravity driven, without pumps along the sewer network. No detailed 110 hydrodynamic model of the catchment was available during the study. Relevant data for the area 111 were provided by the local water utility, and they included shape files of the gravity sewer network, 112 boundaries of the catchment area, geographical location of potable water consumption points along 113 the distribution system (around 28,000 points), and the potable water consumption for each point 114 over a reference period (1 year, from January to December 2016). WWTP influent flow data (at 5115 minute resolution) were also available for the study period. The average potable water consumption 116 in the study area is $0.22 \mathrm{~m}^{3} \mathrm{inh}^{-1} \mathrm{~d}^{-1}$ (ISTAT, 2018).

\subsection{The approach}

\subsubsection{Identification of sub-catchments}

120 The wastewater discharge points (assumed to coincide with the GIS location of potable water consumption points) were grouped into sub-catchments based on three steps:

i) the shortest in-sewer distance between each point and the WWTP was calculated using the Dijkstra's algorithm (Cormen, 2001; see Supplementary Information for more information on the algorithm), available in ArcGIS 10.3 (ESRI);

ii) distances were input to the iterative Expectation-Maximation (EM) algorithm to fit a Gaussian mixture model (Reynolds, 2015), optimizing the likelihood function of a number of probability density functions (we called them as virtual sub-catchments due to their mathematical nature). The number $n$ of virtual sub-catchments was varied from 1 
to 30 (considered as the highest number feasibly described by a conceptual model), and the number that minimised the Bayesian Information Criterion (BIC) was selected;

iii) each wastewater discharge point was assigned to the virtual sub-catchment that maximised its probability density function, providing a geographical representation.

Step ii and iii were coded in Matlab R2016a (Mathworks).

\subsubsection{Estimation of dry-weather flow parameters}

Two dry-weather parameters were estimated, namely the in-sewer flow velocity $v$ and the total infiltration flow $Q_{\text {inf,tot }}$ The in-sewer flow velocity $v\left[\mathrm{~m} \mathrm{~s}^{-1}\right]$, assumed constant in the catchment due

$$
H R T_{i}=\frac{d_{i}}{v}
$$

to the flat characteristic of the urban area, is linked to the $H R T$ in each sub-catchment (Eq. 1):

where $d_{i}[\mathrm{~m}]$ is the average in-sewer distance of the $\mathrm{i}^{\text {th }}$ sub-catchment.

The optimization relied on a simple simplex search algorithm (Nelder et al., 1964) and minimized the root mean square error (RMSE) between the Measured Flow Pattern $(M F P)$ and the calculated wastewater flow at the inlet of the WWTP (eq. 2):

$$
\min _{v, Q_{\text {inf }, t o t}} R M S E\left(\sum_{i=1}^{n} Q_{P W, i}\left(t+H R T_{i}\right)(1-\alpha)+Q_{\text {inf }, \text { tot }}, M F P(t)\right)
$$

where $Q_{P W, i}(t)\left[\mathrm{m}^{3} \mathrm{~s}^{-1}\right]$ is the potable water consumption of the $\mathrm{i}^{\text {th }}$ sub-catchment ( $n$ in total), calculated as the sum of the potable water consumed by all points within the $\mathrm{i}^{\text {th }}$ sub-catchment and normalized by a typical daily consumption profile (Candelieri and Archetti, 2014), $\alpha$ [-] is the water loss factor (due to e.g. gardening), assumed equal to 0.02 (Butler et al., 2004), and $Q_{i n f, t o t}\left[\mathrm{~m}^{3} \mathrm{~s}^{-1}\right]$ is the total infiltration flow considering the entire catchment. $M F P(t)$ was obtained by aggregating dry-weather flow data (excluding weekends and holiday periods) on an hourly basis to generate a daily flow pattern with its confidence interval $\left(5^{\text {th }}\right.$ and $95^{\text {th }}$ percentile). 


\subsubsection{Building the conceptual model}

153 The conceptual model was built by combining elements of the IUWS_MP library (Vezzaro et al., 154 2014), implemented in WEST 2014® (DHI A/S, Denmark). The elements allow simulating 155 wastewater/MPs generation at the household level (source), wastewater transport and MP 156 transformation processes (e.g. volatilization, sorption, aerobic biodegradation, etc.) in different 157 parts of the urban drainage system (e.g. sewer, WWTP, river). For our case study, each sub158 catchment was modelled as a wastewater source and a sewer system. Wastewater generation is 159 simulated by considering the main characteristics of the systems (population density, capita daily 160 wastewater production, groundwater infiltration, etc. - see Supplementary Information).

161 The sewer system was modelled as a series of CSTRs, whose number was iteratively adjusted to 162 match the $H R T_{i}$ obtained from section 2.2.2 (see Supplementary Information). Verification of the 163 multi-catchment model was performed by comparing the simulated dry weather flow (sum of the 164 contributions of each sub-catchment) at the WWTP location with flow measurements (the $M F P(t)$ 165 pattern obtained in section 2.2.2 was used).

\subsection{Scenario analysis}

\subsubsection{Comparison of conceptual model structures}

169 The performance of the multi-catchment model in simulating in-sewer MP fate was compared 170 against a classical single-catchment model. The latter was built using a single series of CSTRs, 171 whose number was adjusted to simulate an average $H R T^{*}$ defined as the flow-weighted average of 172 the $H R T_{i}$ of each sub-catchment. Model verification was also performed with flow measurements at 173 the WWTP as for the multi-catchment model (see section 2.2.2).

174 The fate of an ideal reactive non-sorptive MP, which can undergo biodegradation and retransformation, was simulated with both models for two types of inputs: 
i) a pulse input (less than 1 hour), which refers to a compound with a relative small usage and/or discharged predominantly from few points (e.g. hospital or manufacturing facility);

ii) a continuous input (over 24 hours following the same flow pattern), which refers to a substance with a relatively high consumption. An average concentration of $\sim 2.5 \mu \mathrm{g} \mathrm{L}^{-1}$ was selected as representative (Galus et al., 2013; Fent et al., 2006; Daughton and Ternes, 1999) to be emitted (where the sum of the individual contributions of each subcatchment, proportionally to its size, was equal to the total contribution from discharge in the single-catchment).

The model output was calculated for the inlet of the WWTP. Five performance indicators, four for the pulse input (eq. 3, 4, 5 and 6) and one for the continuous input (eq. 7) were derived in Matlab 2016a: 1) the cumulative load [g] entering the WWTP (eq. 3); 2) the removal efficiency [\%] during in-sewer transport (eq. 4); 3) the peak delay [min] (eq. 5); the pulse duration [min] (eq. 6); and the average concentration $\bar{C}\left[\mu \mathrm{g} \mathrm{L}^{-1}\right]$ derived to mimic a 24-hour flow-proportional composite sampler with 10-minute sampling frequency (eq. 7).

$$
\begin{gathered}
\text { Cumulative load }=\int_{t_{\text {start }}}^{t_{\text {end }}} C(t) Q(t) d t \\
\text { Removal efficiency }=\frac{\text { pulse input }- \text { cumulative load }}{\text { pulse input }} \\
\text { Peak delay }=t\left(C_{\max }\right)-t_{\text {release }} \\
\text { Pulse duration }=t\left(C_{99}\right)-t\left(C_{1}\right) \\
\bar{C}=\frac{\sum C(t) Q(t)}{\sum Q(t)}
\end{gathered}
$$

192 where $C\left[\mu \mathrm{g} \mathrm{L}^{-1}\right]$ stands for the MP concentration and $C_{\max }, C_{1}$ and $C_{99}$ are the maximum, $1^{\text {st }}$ and $19399^{\text {th }}$ percentile concentrations, respectively; $Q\left[\mathrm{~m}^{3} \mathrm{~d}^{-1}\right]$ is the wastewater flow; $t_{\text {start }}$ and $t_{\text {end }}[\mathrm{min}]$ are 
194 the initial and final time of the simulation, respectively and, $t_{\text {release }}[\mathrm{min}]$ is the releasing time of the 195 pulse.

196 The comparison between the two conceptual models was based on the percentage deviation [\%] 197 between values of the above indicators derived for the single-catchment and the multi-catchment 198 model (eq. 8):

$$
\text { Deviation }=\frac{\text { indicator }_{\text {multi-catchment }}-\text { indicator }_{\text {single-catchment }}}{\text { indicator }_{\text {single-catchment }}} \quad \text { Eq. } 8
$$

\subsubsection{Simulated scenarios}

202 Three scenarios were investigated, focusing on the effect of biodegradation kinetics (Scenario 1), 203 simultaneous biodegradation and retransformation kinetics (Scenario 2) and geographical location 204 of point sources of emission (Scenario 3):

205 - Scenario 1: Effect of biodegradation. Six biodegradation half-life values of $12 \mathrm{~min}, 20$ $206 \min , 2.5 \mathrm{~h}, 4.5 \mathrm{~h}, 40 \mathrm{~h}$ and $1000 \mathrm{~h}$ were chosen to mimic the behaviour of a broad range of easily (e.g. ibuprofen), moderately (e.g. furosemide) and not biodegradable/recalcitrant (e.g. carbamazepine) substances. The selected half-life values lump the biodegradation by suspended microorganisms and biofilms in sewer, which have found to be both active in the

- Scenario 2: Effect of complex retransformation pathways. We evaluated the impact of retransformation processes on model predictions for MPs that simultaneously undergo biodegradation. In the IUWS_MP library, we implemented retransformation as reported in Equations 9 and 10, similarly to the approach used by Plósz et al. (2010, 2012):

$$
\frac{d S_{M P_{r e t}}}{d t}=-k_{r e t} S_{M P_{r e t}}
$$




$$
\frac{d S_{M P}}{d t}=-k S_{M P}+k_{r e t} S_{M P_{r e t}}
$$

where $k_{\text {ret }}\left[\mathrm{d}^{-1}\right]$ and $k\left[\mathrm{~d}^{-1}\right]$ are the first-order rate of retransformation and biodegradation, respectively; $S_{M P}\left[\mathrm{~g} \mathrm{~m}^{-3}\right]$ and $S_{M P r e t}\left[\mathrm{~g} \mathrm{~m}^{-3}\right]$ are the concentrations of the parent and retransformable fractions, respectively. Three half-life values for retransformation (20 min, $2.5 \mathrm{~h}$ and $40 \mathrm{~h}$, were selected to mimic retransformable fractions that can quickly transform back to their respective parent compounds (e.g. glucuronide conjugates) or are relatively stable (e.g. sulphate conjugates) (Gomes et al., 2009). Two types of proportions (1 and 10) parameters were tested (see Table S3 in SI). between the released concentration of the parent MP and its retransformable fractions were selected, based on typical values found in raw wastewater (Khan and Ongerth, 2003; Bahlmann et al., 2014). All the possible combinations between the above-mentioned 


\section{Results and discussion}

\section{3}

234

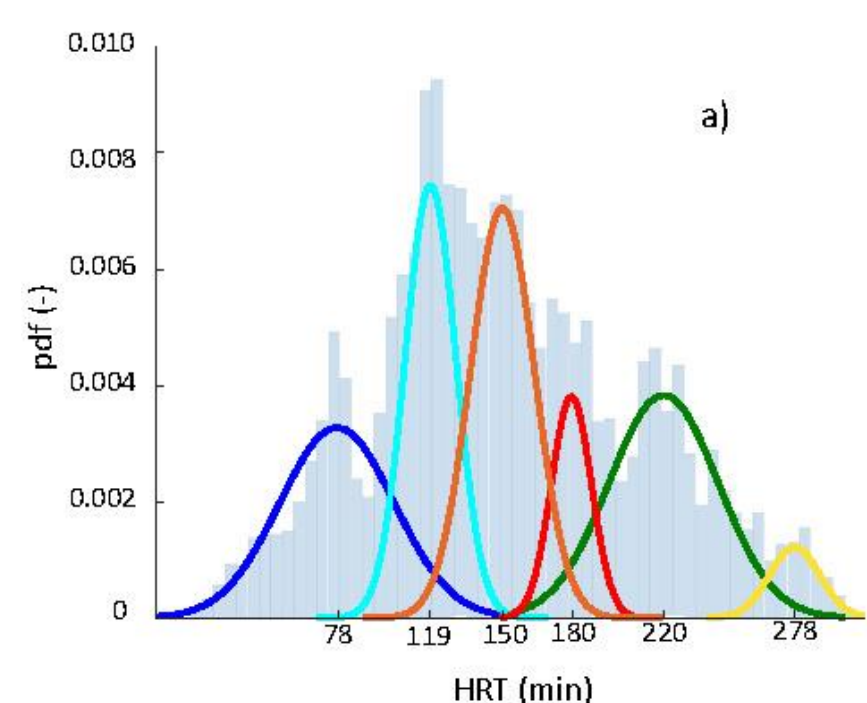

Discharge points

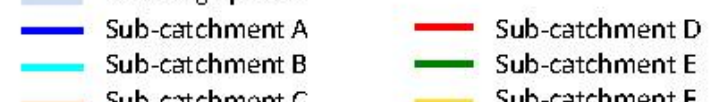

Sub-catchment $C \quad$ Sub-catchment $F$

\subsection{Conceptual model structure}

\subsubsection{Identification of sub-catchments}

The cluster analysis resulted in the identification of six virtual sub-catchments (Figure 1a), for a minimum BIC value of $3.10 \cdot 10^{5}$ (ranging from $3.13 \cdot 10^{5}$ to $3.11 \cdot 10^{5}$ for 1 and 30 catchments, respectively). Figure $1 \mathrm{~b}$ shows the geographical representation of the sub-catchments based on the location of the wastewater discharge points. The usefulness of an objective over a heuristic approach can be appreciated when considering sub-catchments $\mathrm{C}$ and D. While their geographical location (Figure 1b) would suggest considering them as unique catchment, the cluster analysis clearly highlighted two distinct $H R T$ peaks of 150 and 180 min (Figure 1a). This 30-minute difference may influence fate estimations for degradable MPs (half-life $\leq 1 \mathrm{~h}$ ).

Figure 1. (a) Results of the cluster analysis with identification of the virtual sub-catchments. (b) Geographical representation of the virtual sub-catchments based on the location of the wastewater discharge points.

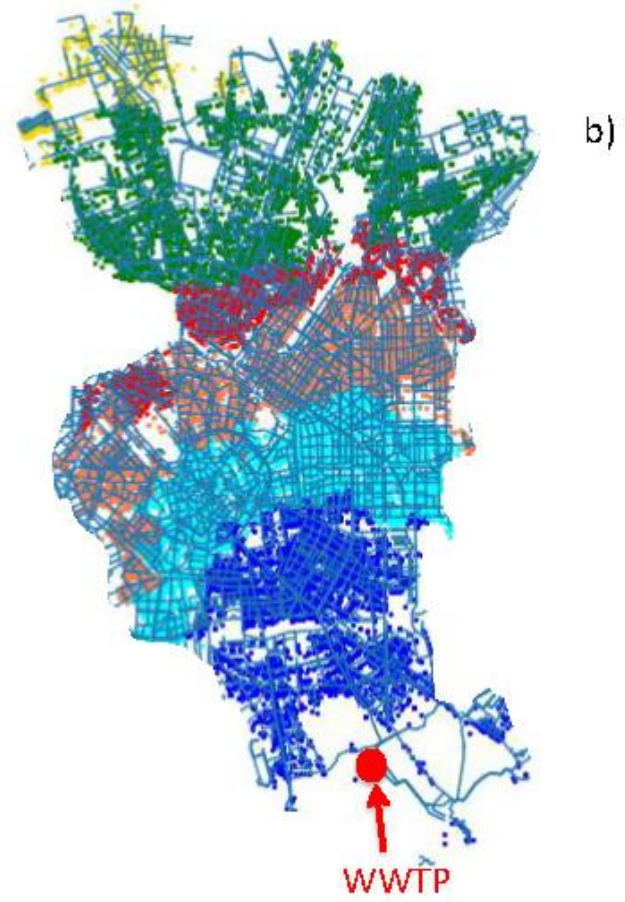


249 The calibration of dry-weather MFP (RMSE value of $0.16 \mathrm{~m}^{3} \mathrm{~s}^{-1}$ ) resulted in a total infiltration flow $250 Q_{\text {inf,tot }}$ and in-sewer flow velocity $v$ of $1.0 \mathrm{~m}^{3} \mathrm{~s}^{-1}$ and $0.8 \mathrm{~m} \mathrm{~s}^{-1}$, respectively. $Q_{\text {inf,tot }}$ corresponded to $25124 \%$ of the dry-weather flow and $v$ fell within typical ranges for gravity sewer systems (Butler et 252 al., 2004). The estimated $H R T$ distribution had a flow-weighted average of 150 min (equal to $253 H R T^{*}$ ) and $H R T_{i}$ values were placed at seemingly rather regular intervals (on average $40 \mathrm{~min}$ ), 254 ranging from 78 to 278 min (Figure 1a). These intervals depend on the shape of the $H R T$ 255 distribution (unique for every urban catchment) and should not be extrapolated for sub-catchment 256 identification in other urban catchments.

\subsubsection{Development of the conceptual model}

259 A multi-catchment model (Figure 2a) was developed based on the results of the previous two steps.

260 Model parameters were set as described in section 2.2.3 and reported in Table 1 where population 261 density $\rho\left(18816\right.$ inh $\left.\mathrm{km}^{-2}\right)$, wastewater production $W W P\left(0.218 \mathrm{~m}^{3} \mathrm{inh}^{-1} \mathrm{~d}^{-1}\right)$ and infiltration flow Ifl

$262\left(0.145 \mathrm{~m}^{3} \mathrm{~s}^{-1} \mathrm{~km}^{-2}\right)$ were equal in each sub-catchment. The relative deviation between simulated and 263 estimated $H R T_{i}$ was small (<6\%) for each sub-catchment, indicating a proper fit (see Table S2). As 264 for the single-catchment model, model parameters are also reported in Table 1, and the relative 265 deviation between simulated and estimated $H R T^{*}$ and the relative deviation was also small (3\%).

266 Model verification using measured and simulated flow data can be seen in Figure $2 \mathrm{~b}$. The simulated 267 dry-weather flow was within the confidence interval of the measured flow data, indicating an 268 adequate description of the influent flow by both models.

Table 1. Conceptual model parameters

\begin{tabular}{cccccccc}
\hline & \multicolumn{1}{c}{ Multi-catchment } & Single-catchment \\
\hline Sub-catchment & A & B & C & D & E & F & - \\
A $\left(\mathrm{km}^{2}\right)$ & 13.1 & 16.4 & 17.5 & 6.6 & 13.8 & 2.2 & 69 \\
Number of tanks & 5 & 8 & 9 & 10 & 12 & 12 & 12 \\
\hline
\end{tabular}



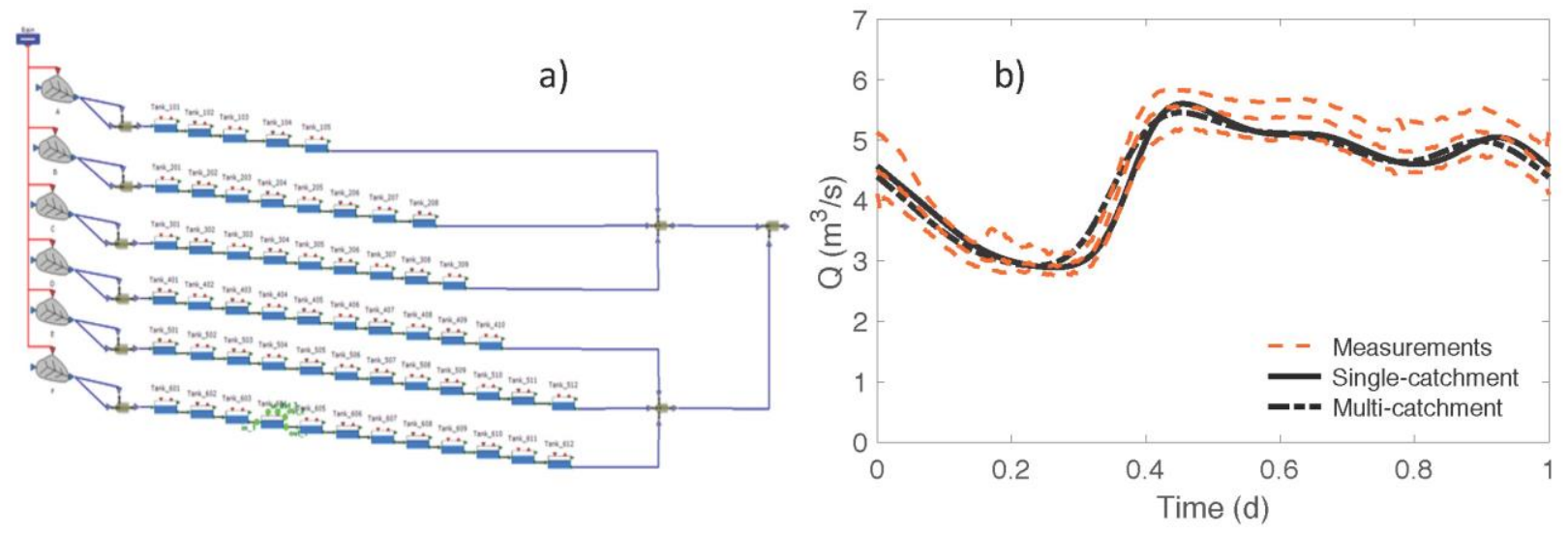

273 Figure 2. (a) Conceptual model in WEST®. (b) Model verification: measurements median and $5^{\text {th }}$ and $95^{\text {th }}$ 274 percentiles (dashed orange line), and model simulations (solid and dash black line).

\subsection{Scenario analysis}

\subsubsection{Scenario 1-Effect of degradation}

Pulse source. The results from the simulations of a moderately biodegradable MP (half-life $=2.5 \mathrm{~h}$ )

are shown in Figure 3a. The pulse input resulted in bell-shaped curves, where the simulation of advection and biodegradation led to a reduction of the area below the curves. The estimated cumulative load and removal efficiency, and the corresponding deviation, for the whole range of tested biodegradation half-lives is shown in Figure $3 \mathrm{c}$ and $3 \mathrm{e}$, respectively. The cumulative load deviation ranged from $0 \%$ to $312 \%$ (Figure 3c), being larger than $10 \%$ for MPs with half-lives $\leq 2.5$ $\mathrm{h}$ and negligible or null value $(5 \%, 1 \%$ and $0 \%)$ for the more recalcitrant MPs. Hence, the predicted loads entering the WWTP were overall higher for the multi-catchment model. As to in-sewer removal efficiency, deviations ranged from $-15 \%$ to $0 \%$ (Figure $3 \mathrm{e}$ ), showing that the multicatchment model predicted lower removal efficiencies than the single-catchment model, especially for MPs with half-lives $=2.5 \mathrm{~h}$ and $4.5 \mathrm{~h}$. The analysis of the peak delay indicator (Figure S1) showed that the multi-catchment model predicts the peak load entering the WWTP earlier than the single-catchment model (deviation ranging from $-9 \%$ to $-6 \%$, corresponding to a difference between 
291 the models of 70 to 50 minutes). This is mainly due to the contribution of the closest sub-catchment 292 to the WWTP (indicated in blue in Figure 1b), for which MP release occurs sooner than the other 293 sub-catchments due to its short $H R T$ (78 $\mathrm{min})$. Deviations for the pulse duration (see Figure $\mathrm{S} 1$ ) 294 indicated that the a pulse takes longer to be completely release for the multi-catchment model 295 (deviation ranging from $6 \%$ to $21 \%$, corresponding to 20 to 90 minutes differences between the 296 models).

297 Continuous source. The model results for a continuous input of a moderately biodegradable MP 298 (half-life equal to $2.5 \mathrm{~h}$ ) are shown in Figure 3b. The 24-h composite concentration and the 299 deviation for all the whole range of substances (from easily biodegradable to recalcitrant) are shown 300 in Figure 3d. The models predicted different concentrations for half-life lower than $2.5 \mathrm{~h}$ (deviation 301 equal to $\sim 10 \%$ ), with a maximum deviation of $350 \%$ for half-life of $0.2 \mathrm{~h}$. In these cases, the 302 percentage deviation between the two models was higher than the uncertainty typically associated 303 to analytics, quantifiable in 20-30\% (Ort et al., 2009; Castiglioni et al., 2012), thus indicating a 304 considerably lower estimated concentrations at the WWTP inlet with the single-catchment model. 305 Notably, a high deviation (e.g., 350\%) corresponded to small concentration differences (e.g. < 0.2 $\left.306 \mu \mathrm{g} \mathrm{L}^{-1}\right)$ due to the low input concentrations $\left(\sim 2.5 \mu \mathrm{g} \mathrm{L}^{-1}\right)$ that were used for simulations. On the 307 other hand, higher input concentrations (e.g. $100 \mu \mathrm{g} \mathrm{L}^{-1}$ ) would lead, for the same deviation, to 308 higher concentration differences (e.g. $<8 \mu \mathrm{g} \mathrm{L}^{-1}$ ).

309 Predicted removal efficiencies were generally in good agreement with measurements from pilot310 and full-scale sewer studies with degradable and persistent MPs (Table S4). Findings of both 311 scenarios highlighted how the proposed approach supported the development of an appropriate 312 model structure for predictions of biodegradable MPs with half-life close to or below the average $313 H R T$ of the catchment (150 $\mathrm{min})$. 


\section{Pulse}

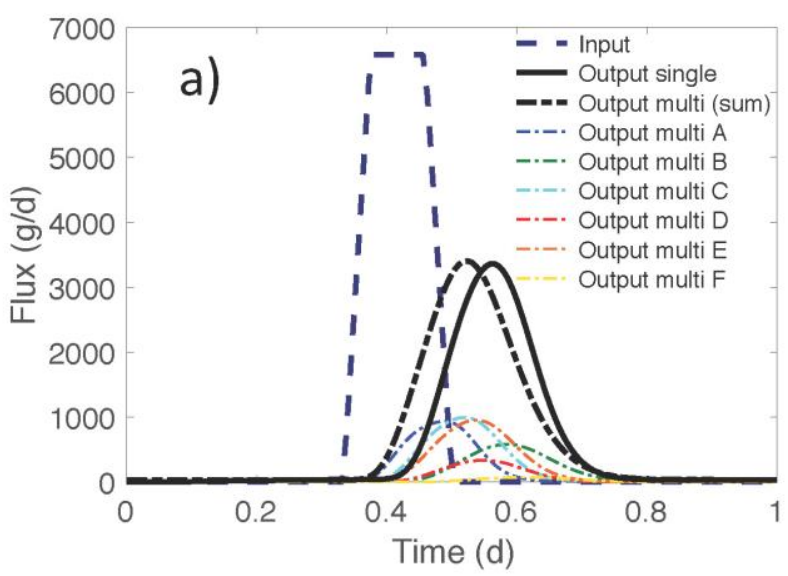

Continuous
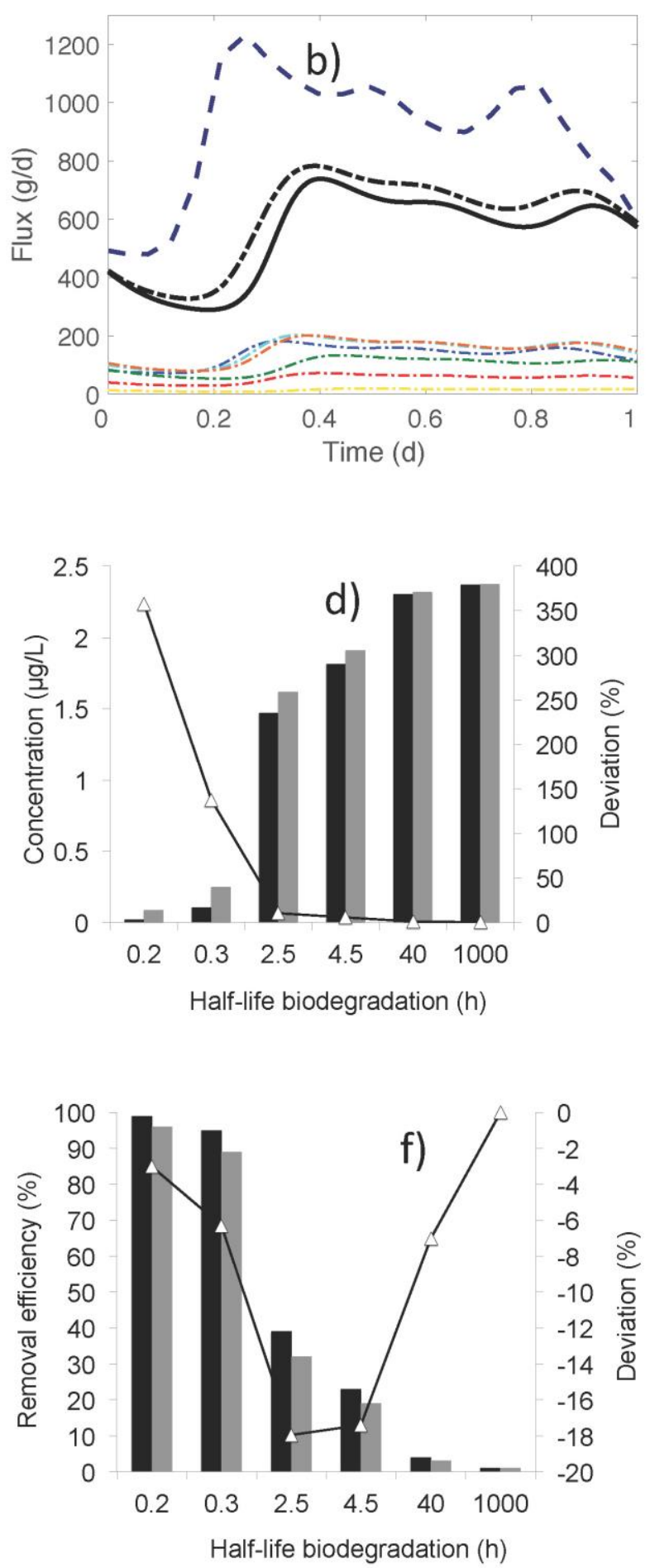
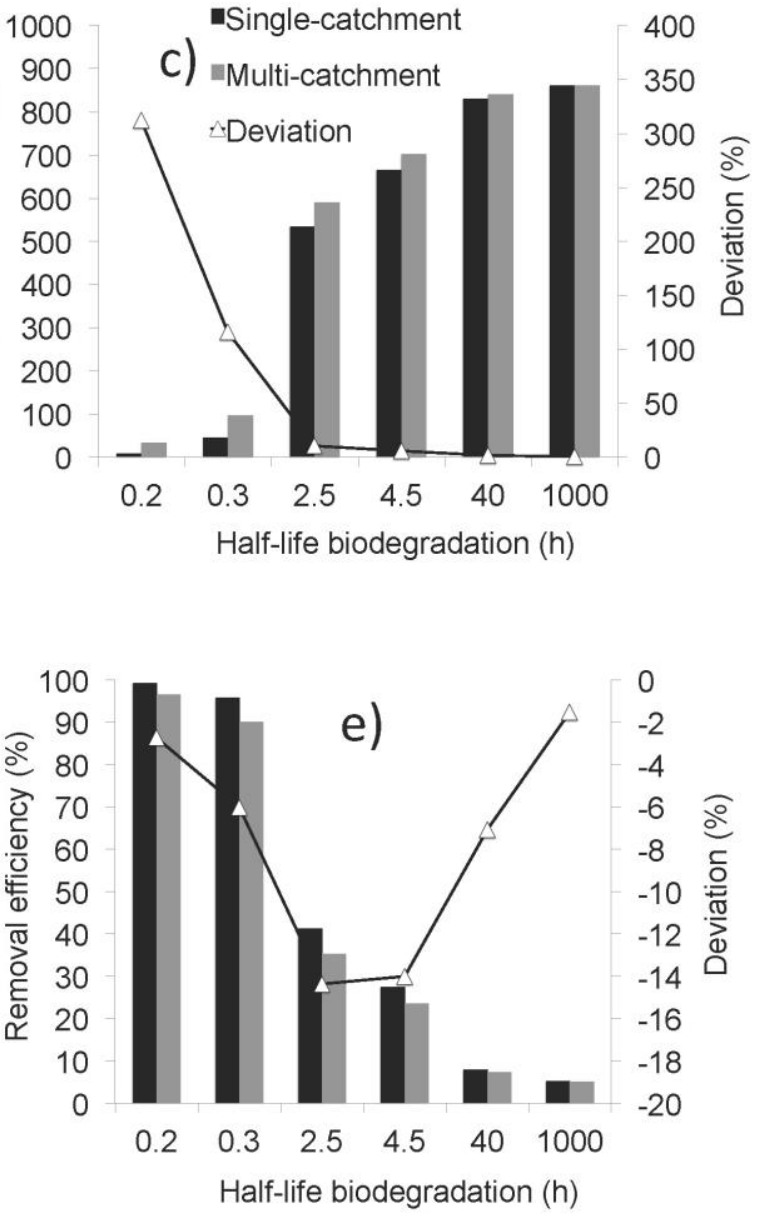

315 Figure 3. Model response for a moderately biodegradable MP (half-life of $2.5 \mathrm{~h}$ ) for (a) pulse input and (b) continuous input. Calculated (c) cumulative load, (d) average concentration and (e and f) removal efficiency 
317 for the single catchment model (black bar) and multi-catchment model (grey bar) with the corresponding 318 percentage deviation (solid triangle) for different half-life.

\subsubsection{Scenario 2 - Effect of complex transformation pathways}

321 The impact of retransformation on single- and multi-catchment model predictions was assessed for parent MPs with biodegradation half-life equal to $2.5 \mathrm{~h}$ and $40 \mathrm{~h}$. These two values were selected to describe easily-to-moderately biodegradable and recalcitrant, MPs, respectively. Furthermore, results from Scenario 1 showed that deviation between model predictions for these half-lives was $\leq 10 \%$, hence retransformation may potentially increase such deviation.

Pulse source. The effect of simultaneous biodegradation and formation in the sewer on the fate of MPs was assessed by considering the removal efficiency as relevant indicator (Figure 4). Nearly all simulations predicted negative removal efficiency (Figure 4a), suggesting that retransformation can strongly affect MP fate during in-sewer transport. Very low values, ranging from $-950 \%$ and $400 \%$, were estimated for MPs which undergo retransformation rapidly (half-life $\leq 2.5 \mathrm{~h}$ ) and when high retransformable fractions were present. When retransformation was slow (half-life $=40 \mathrm{~h}$ ) or retransformable fractions were comparable to the one of parent compound, removal efficiencies ranged from $-100 \%$ to $35 \%$. This suggests a minor but not negligible effect of retransformable 334 fractions on the parent compound estimation. Figure $4 \mathrm{c}$ presents the comparison between multi- and 335 single-catchment predictions in terms of deviation of removal efficiency. For moderately biodegradable MPs (biodegradation half-life $=2.5 \mathrm{~h}$ ) the deviation was around $-7 \%$ on average 337 (with a minimum of $-35 \%$ ), indicating that lower MP loads were estimated with the singlecatchment model. Conversely, the deviation for hardly biodegradable MPs (biodegradation half-life $339=40 \mathrm{~h}$ ) was $16 \%$ on average (with a maximum of $50 \%$ ), suggesting that the single-catchment model 340 provided higher estimation of the MP loads entering the WWTP.

341 Continuous source. Predicted influent concentrations by multi-catchment and single-catchment models are presented in Figure 4b. A wide range of concentrations (3-26 $\mu \mathrm{g} \mathrm{L}^{-1}$ ) was obtained. 
343 Specifically, the faster the retransformable fractions retransform, the more important is the effect of

344 the retransformation and retransformable fraction initial concentration on the parent compound 345 concentration. For example, when the retransformation half-life was $0.3 \mathrm{~h}$, parent MP 346 concentrations differed significantly depending on biodegradable half-life and initial proportion, 347 while almost no differences in concentrations were observed for a retransformation half-life of $40 \mathrm{~h}$. 348 Deviations between multi-catchment and single-catchment predictions (Figure 4d) ranged between $34910 \%$ and $-12 \%$, exhibiting higher values than the ones reported for the continuous source in the 350 scenario 1 (section 3.2.1).

351 Notably, negative removal efficiencies (down to -66\%) have been also measured in pilot- and full352 scale sewer studies (Table S4). The availability of empirical data is nevertheless limited as 353 compared to Scenario 1, as most studies have been relied on spiking of parent MPs alone.

354 Findings of both scenarios suggested that deviations between the models increased when 355 retransformation processes were considered. Specifically, the single-catchment model provided 356 either higher or lower estimation of removal efficiency/concentration without following any 357 particular trend, probably due to the non-linear interactions between the investigated parameters. 


\section{Pulse}
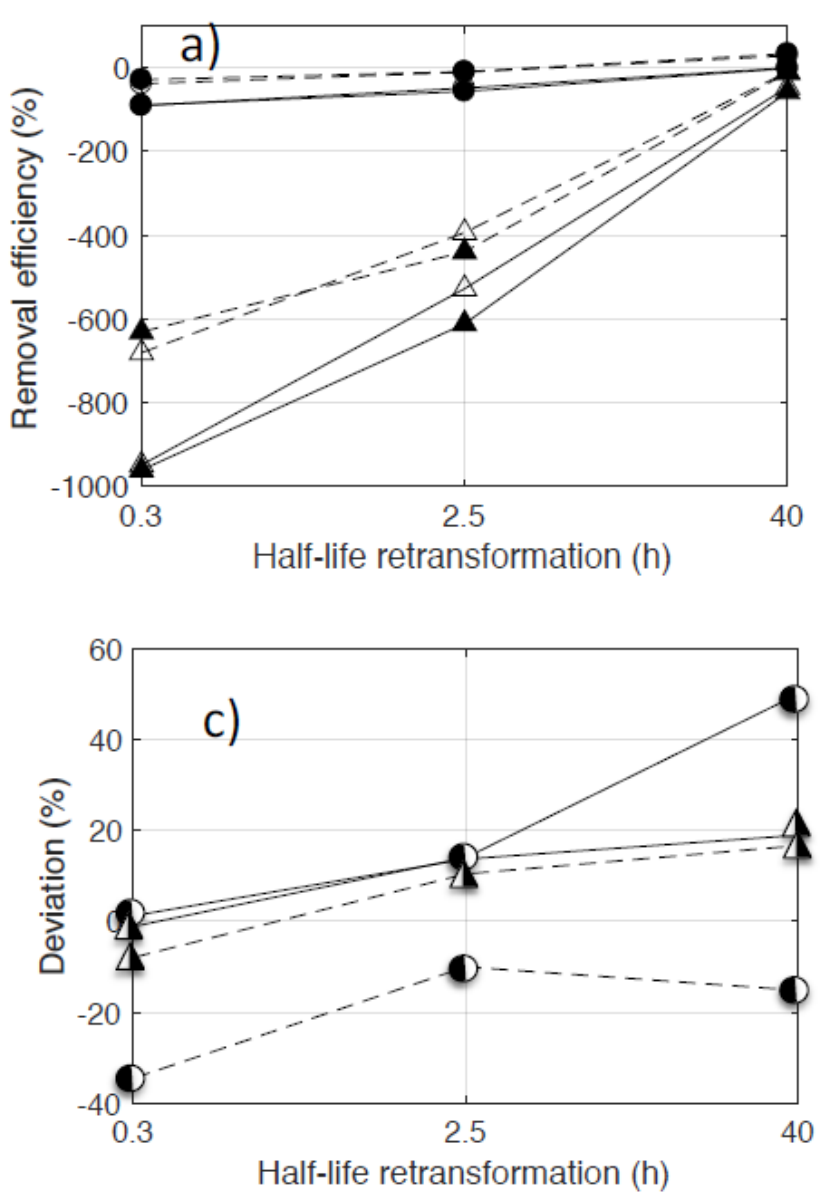

Continuous
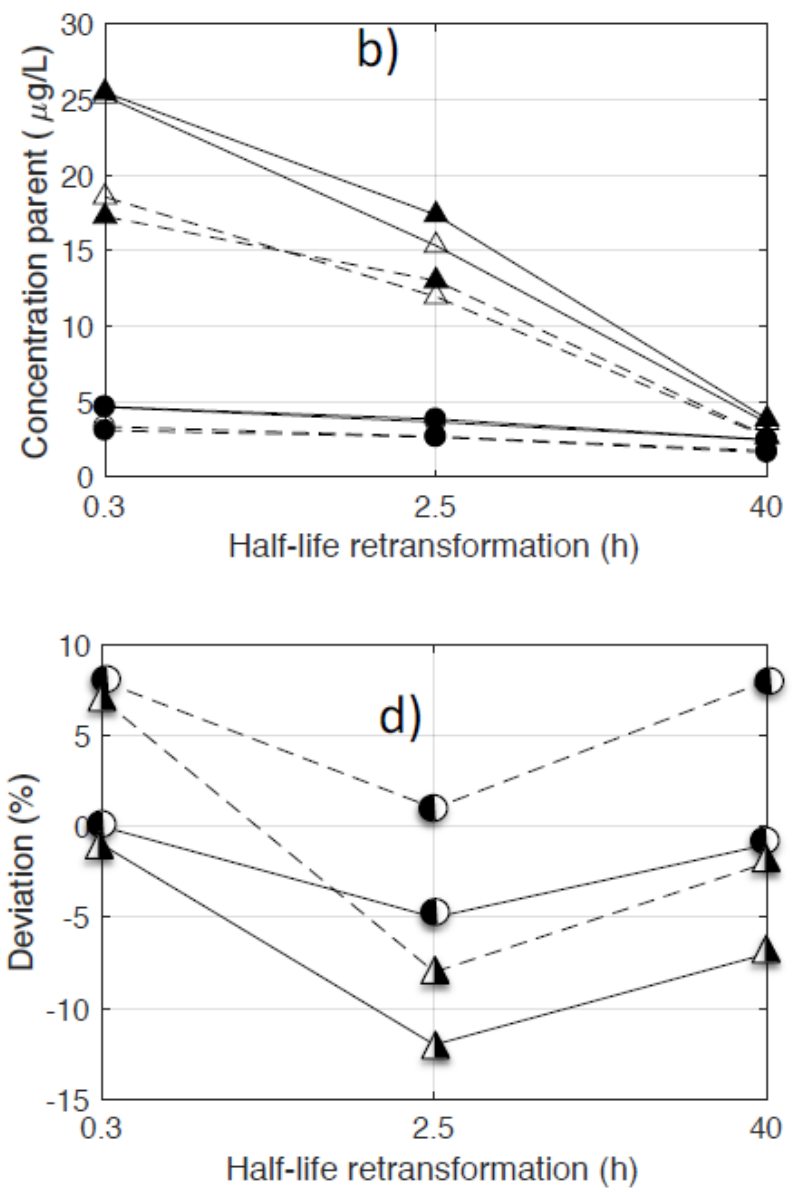

$\Delta$ Deviation
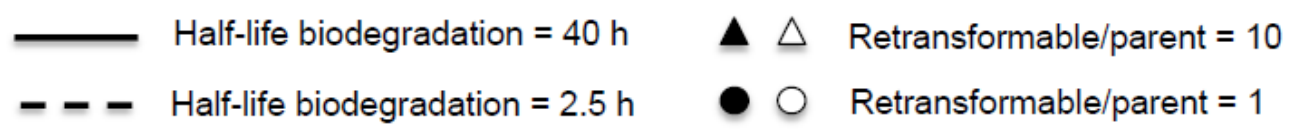

(1)

Figure 4. (a) Calculated removal efficiency and (b) average parent concentration by single-catchment (black triangle and black circle) and multi-catchment (white triangle and white circle) models for different initial conditions. Deviation for (c) removal efficiency and (d) average parent concentration.

\subsubsection{Scenario 3 - Effect of point source location}

Simulation results for easily (half-life $=12 \mathrm{~min}$ ), moderately (half-life $=2.5 \mathrm{~h}$ ) and hardly biodegradable (half-life $=40 \mathrm{~h}$ ) MPs discharged from two different locations in the catchment are shown in Figure 5. Corresponding removal efficiencies, and their comparison with efficiencies derived from the single-catchment model, are reported in Table S5 (SI). 
369 Results show that both location and MP biodegradability affected the MP loads entering the WWTP. The impact of point source location significantly affected the removal efficiency for easily and especially moderately biodegradable MPs (from 19\% to $46 \%$ change), for which a considerable deviation was also shown from the single-catchment prediction (-49-24\%). Conversely, discharge from different locations had a limited impact on in-sewer removal efficiencies for a hardly 374 biodegradable compound (2\%-5\%).

375 Overall, these results indicate that the extent of in-sewer attenuation processes for degradable MPs is associated with the spatial distribution of discharge sources. In this context, point sources of discharge require special consideration, and limited in-sewer attenuation may be decisive for the implementation of an in situ pre-treatment to minimize MP loads to WWTPs (Scott et al., 2018).

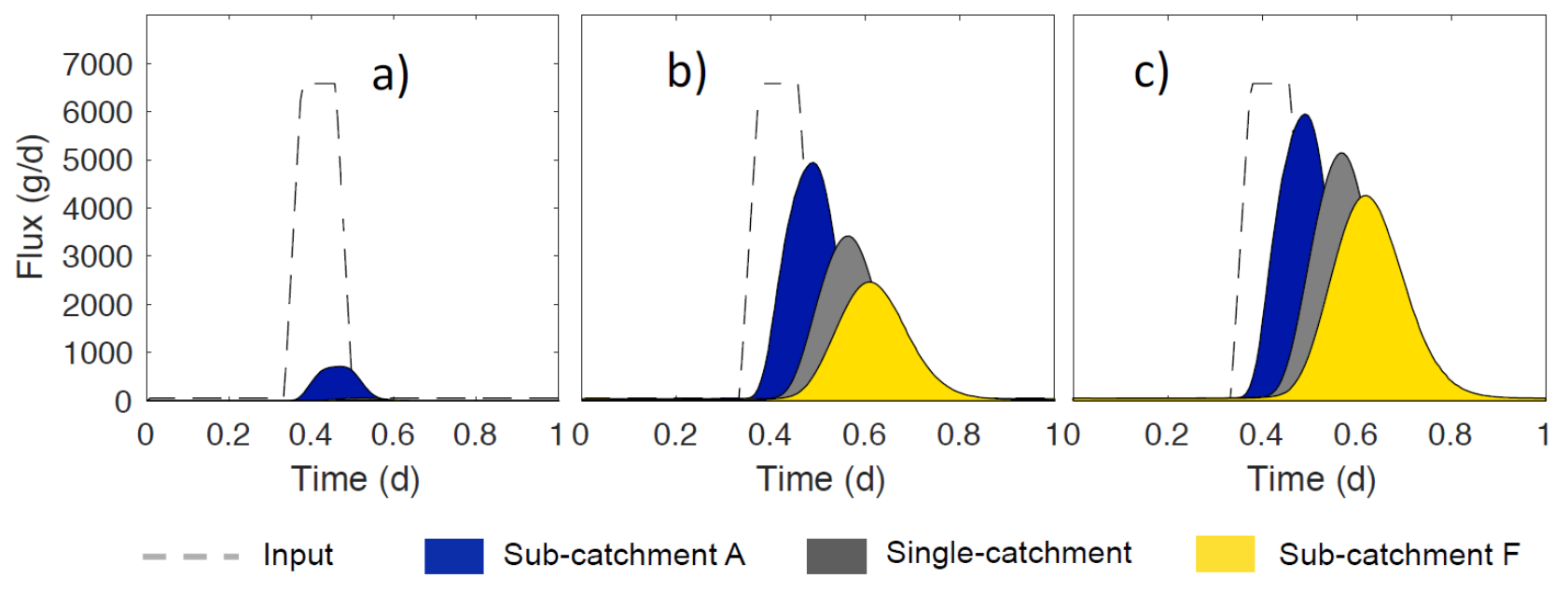

Figure 5. Estimated flux entering the WWTP of (a) a readily biodegradable, (b) moderately and (c) hardly biodegradable MP, based on point source location (sub-catchment A and F) and model conceptualization (multi-catchment and single-catchment).

\subsection{Applicability, data requirements and future perspectives}

This study presents a methodology for systematic construction of conceptual sewer models in large urban catchments with the intent of simulating the fate of reactive, non-sorptive MPs. The approach 
can be held valid under dry-weather conditions and during small rain events, i.e. when $H R T$ is not significantly different. The applicability to medium events (resulting e.g. in combined sewer overflows (CSO), or wastewater detention in storage basins) would require a model structure including the addition of the most relevant points of the network. Moreover, the model can thus be used as decision-support on whether pre-treatment at the point source is needed before discharge or in-sewer attenuation is sufficient to reduce MP loads to WWTP.

394 As for the data requirement, the method required the location of the wastewater discharge points along the sewer network. In this work, we used the location of potable water consumption points $(28,000)$ as proxy variable for the position of the wastewater discharge points. Alternatively, nodes of the sewer network (McCall et al., 2017) or the centroids of the census block polygons (Kapo et al., 2017) can be used. The sewer network structure is also required, although road networks are a valid alternative as suggested by Kapo et al. (2017). As for the in-sewer flow velocity, an average value was estimated, matching the simulated wastewater flow (derived from potable water consumption) against measurements at the inlet of the WWTP. Alternatively, a design standard velocity could be used (Kapo et al., 2017), although the topography of the area should be carefully considered. In our study, given the flat characteristics of urban area, a unique value was assumed across the catchment. However, different in-sewer flow velocities should be assigned (e.g. to each sub-catchments) to account for different altitudes (resulting in different $H R T s$ ).

Overall, the above-mentioned assumptions can affect the sub-catchment identification and further investigation should be done to assess their sensitivity. Further investigations should also include:

- Wet-weather conditions. Wet-weather conditions are not expected to be relevant when assessing the overall MP loads to the WWTP over long time periods, since they typically represent a minor $(<10 \%)$ fraction of the total WWTP operating time. However, the presence of wet-weather discharges (CSO, WWTP bypass) might require a redefinition of the model structure in order to fully investigate the impacts on the receiving waters. 
- Complexity of the biochemical model. A first-order kinetic for both biodegradation and retransformation process was assumed in the IUWS_MP library. It should be investigated if more complex process description can improve the estimation of the MP fate (e.g. 416 biodegradation rates dependence on total suspended solids-TSS).

- Integration with other elements of the wastewater system. Since the proposed approach can be extended to predict MP fate across the whole integrated wastewater system (including WWTP and recipients), the scenarios investigated in this study (e.g. location of MP point sources) should possibly be replicated with an integrated model. The integrated assessment 421 should mainly focus on moderately-to-hardly biodegradable MPs that are subjected to retransformation processes, for which poor removal in the WWTP or persistence in the environment can pose a risk to receiving water bodies. 


\section{Conclusions}

426 In this study, we present a new systematic approach combining GIS-based information and 427 statistical analysis to identify the optimal structure of a conceptual model for simulating in-sewer $428 H R T$ in a large urban catchment, while keeping model complexity as simple as possible. The 429 approach was developed to improve fate predictions of down-the-drain MPs that undergo 430 degradation and/or formation during transport in sewers. Findings from the study allowed reaching 431 the following conclusions:

- The conceptual modelling approach allowed deriving a multi-catchment model, and the large catchment was subdivided into sub-catchments, each characterized by a typical $H R T$. The obtained model allowed for successful simulation of dry weather flow and is applicable (i) in the absence of a complex hydrodynamic model and (ii) when a single-catchment model (with one average $H R T$ ) is not representative of large urban areas.

Overall, the proposed approach is expected to ease the building of conceptual sewer water quality models, allowing for a broader implementation of integrated models (sewer, WWTP, receiving

\section{Acknowledgments}

448 R.D.C. gratefully acknowledges financial support from Politecnico di Milano, Department of Civil 449 and Environmental Engineering, for his $\mathrm{PhD}$ research fellowship. 
450 The code for the conceptual model construction approach developed in this study is freely available

451 upon request.

\section{References}

454 Bahlmann, A., Brack, W., Schneider, R.J. and Krauss, M. (2014) Carbamazepine and its 455 metabolites in wastewater: Analytical pitfalls and occurrence in Germany and Portugal. $456 \quad$ Water Res 57, 104-114.

457 Butler, D. and Davies J.W. (2004). Urban Drainage (Second edition). CRC Press, London, UK. 458 Candelieri, A. and Archetti, F. (2014). Identify typical urban water demand pattern for a 459 reliable short-term forecasting - The icewater project approach. Procedia Engineering, 89, $460 \quad 1004-1012$.

461 Castiglioni, S., Bijlsma, L., Covaci, A., Emke, E., Hernández, F., Reid, M., Ort, C., Thomas, 462 K.V., van Nuijs, A.L.N., de Voogt, P., Zuccato, E. (2012). Evaluation of uncertainties 463 associated with the determination of community drug use through the measurement of 464 sewage drug biomarkers. Environmental Science and Technology, 47, 1452-1460.

465 Cormen, T. H., Leiserson, C. E., Rivest, R. L., Stein, C. (2001). Dijkstra's algorithm. 466 Introduction to Algorithms (Second ed.). MIT Press and McGraw-Hill, 595-601.

467 D'Ascenzo, G., Di Corcia, A., Gentili, A., Mancini, R., Mastropasqua, R., Nazzari, M., 468 Samperi, R. (2003). Fate of natural estogen conjugates in municipal sewage transport and 469 treatment facilities. Science of the Total Environment, 320, 199-209.

470 Daughton, C.G., Ternes, T.A. (1999). Pharmaceuticals and personal care products in the 471 environment: agents of subtle change? Environmental Health Perspective, 107, 907-938.

472 Davidsen, S., Löwe, R., Thrysøe, C., Arnbjerg-Nielsen, K. (2017). Simplification of one473 dimensional hydraulic networks by automated processes evaluated on 1D/2D deterministic 474 flood models. Journal of Hydroinformatics, 19, 686-700.

475 De Keyser, W., Gevaert, V., Verdonck, F., De Baets, B., Benedetti, L. (2010). An emission time 
series generator for pollutant release modelling in urban areas. Environmental Modelling and Software, 25, 554-561.

Eriksson, E., Revitt, D.M., Ledin, A., Lundy, L., Lutzhoft, H.C.H., Wickman, T., Mikkelsen, P.S., (2011). Water management in cities of the future using emission control strategies for priority hazardous substances. Water Science and Technology, 64, 2109-2118.

Fent K, Weston AA, Carminada D. (2006). Ecotoxicology of human pharmaceuticals. Aquat Toxicol, 76, 122-59.

Flores-Alsina, X., Saagi, R., Lindblom, E., Thirsing, C., Thornberg, D., Gernaey, K. V., and Jeppsson, U. (2014). Calibration and validation of a phenomenological influent pollutant disturbance scenario generator using full-scale data. Water Research, 51(0), 172-185.

Galus, M., Jeyaranjaan, J., Smith, E., Li, H., Metcalfe, C., Wilson, J.Y. (2013) Chronic effects 488 of exposure to a pharmaceutical mixture and municipal wastewater in zebrafish, Aquatic Toxicol, 132-133 212-222.

Gomes, R. L., Scrimshaw, M. D. and Lester J. N. (2009). Fate of conjugated natural and synthetic steroid estrogens in crude sewage and activated sludge batch studies. Environmental Science and Technology, 43, 3612-3618. 493 http://dati.istat.it/Index.aspx?DataSetCode=DCCV_INDACQDOM\# (Accessed 15 April 494 2018).

495 Jelic, A., Rodriguez-Mozaz S., Barceló, D., Gutierrez, O. (2015). Impact of in-sewer 496 transformation on 43 pharmaceuticals in a pressurized sewer under anaerobic conditions. $497 \quad$ Water Research 68, 98-108.

498 Kapo, K. E., Paschka, M., Vamshi, R., Sebasky, M., McDonough K. (2017). Estimation of 499 U.S. sewer residence time distributions for national-scale risk assessment of down-the-drain 500 chemicals. Science of the Total Environment 603-604, 445-452. 
501 Khan, S. J. and Ongerth J. E. (2004). Modelling of pharmaceutical residues in Australian 502 sewage by quantities of use and fugacity calculations. Chemosphere, 54, 355-367.

503 Launay, M.A., Dittmer, U. and Steinmetz, H. (2016) Organic micropollutants discharged by 504 combined sewer overflows - Characterisation of pollutant sources and stormwater-related $505 \quad$ processes. Water Res 104, 82-92.

506 Li, J., Gao, J., Thai, P.K., Sun, X., Mueller, J.F., Yuan, Z., Jiang, G. (2018). Stability of illicit 507 drugs as biomarkers in sewers: From lab to reality. Environmental Science and Technology, $508 \quad 52,1561-1570$.

509 Mannina, G., Alida, C., Viviani, G. (2017). Micropollutants throughout an integrated urban 510 drainage model: Sensitivity and uncertainty analysis. Journal of Hydrology, 554, 397-405.

511 Martin, C., Vanrolleghem, P.A., (2014). Analysing, completing, and generating influent data 512 for WWTP modelling: A critical review. Environmental Modelling and Software, 60, 188513201.

514 McCall, A. K., Scheidegger, A., Madry, M.M., Steuer, A.E., Weissbrodt, D.G., Vanrolle ghem, 515 P.A., Kraemer, T., Morgenroth, E., Ort, C. (2016). Influence of different sewer biofilms on 516 transformation rates of drugs. Environmental Science and Technology, 50, 13351-13360.

517 McCall, A. K., Palmitessa, R., Blumensaat, F., Morgenroth, E., Ort, C. (2017). Modeling in518 sewer transformations at catchment scale - implications on drug consumption estimates in 519 wastewater-based epidemiology, Water Research, 122, 655-668.

520 Menzies, J., McDonough, K., McAvoy, D., Federle, T.W. (2017). Biodegradation of nonionic 521 and anionic surfactants in domestic wastewater under simulated sewer conditions. 522 Biodegradation, 28, 1-14.

523 Nelder, J. A., Mead, R. (1964). A simplex method for function minimization. The Computer $524 \quad$ Journal, 7, 308-313.

525 O’Brien, J. W., Banks, A. P. W., Novic, A. J., Mueller, J. F., Jiang, G., Ort, C., Eaglesham, G., 526 Yuan, Z., and Thai, P. K. (2017). Impact of in-Sewer Degradation of Pharmaceutical and 
Personal Care Products (PPCPs) Population Markers on a Population Model. Environmental Science and Technology, 51 (7), 3816-3823.

529 Obropta, C.C., Kardos, J.S., (2007). Review of urban stormwater quality models: 530 Deterministic, stochastic, and hybrid approaches. Journal of the American Water Resource $531 \quad$ Association, 43, 1508-1523.

532 Ort, C., Hollender, J., Schaerer, M., Siegrist, H. (2009). Model-based evaluation of reduction 533 strategies for micropollutants from wastewater treatment plants in complex river networks. 534 Environmental Science and Technology, 43, 3214-3220.

535 Ort C., Schaffner, C., Giger, W., Gujer, W. (2005). Modeling stochastic load variations in sewer systems. Water Science and Technology, 52, 113-122.

537 Petrie, B., Barden, R., Kasprzyk-Hordern, B. (2015). A review on emerging contaminants in 538 wastewaters and the environment: Current knowledge, understudied areas and 539 recommendations for future monitoring. Water Research, 72, 3-27.

540 Plośz, B. G., Leknes, H., Thomas, K. V. (2010). Impacts of competitive inhibition, parent 541 compound formation and partitioning behaviour on the removal of antibiotics in municipal $542 \quad$ wastewater treatment. Environmental Science and Technology, 44 (2), 734-742.

543 Plośz, B. G., Langford, K. H., Thomas, K. V. (2012). An activated sludge modeling framework 544 for xenobiotic trace chemicals (ASM-X): Assessment of diclofenac and carbamazepine. $545 \quad$ Biotechnology and Bioengineering, 109 (11), 2757-2769.

546 Polesel, F., Andersen, H. R., Trapp, S., Plósz, B. G. (2016). Removal of Antibiotics in 547 Biological Wastewater Treatment Systems-A Critical Assessment Using the Activated 548 Sludge Modeling Framework for Xenobiotics (ASM-X). Environmental Science and 549 Technology, 50 (19), 10316-10334.

550 Pouzol, T., Lévi, Y., Bertrand-Krajewski, J. L. (2018). A Dynamic Pharmaceuticals Loads 551 Source Generator. $11^{\text {th }}$ International Conference on Urban Drainage Modelling, Palermo (Italy). 
553 Ramin, P., Libonati Block A., Polesel F., Causanilles A., Emke, E., de Voogt, P., Plosz, B.G. 554 (2016). Transformation and sorption of illicit drug biomarkers in sewer systems: 555 Understanding the role of suspended solids in raw wastewater. Environmental Science and $556 \quad$ Technology, 50 (24), 13397-13408.

557 Ramin, P., Libonati Block A., Causanilles A., Valverde-Perez, B., Emke, E., de Voogt, P., 558 Polesel F., Plosz, B.G. (2017). Transformation and sorption of illicit drug biomarkers in 559 sewer biofilms. Environmental Science and Technology 51, 10572-10584.

560 Reynolds D. (2015). Gaussian Mixture Models. In: Li S.Z., Jain A.K. (editors) Encyclopedia of 561 Biometrics. Springer, Boston, MA.

562 Saagi, R., Flores-Alsina, X., Fu, G., Butler, D., Gernaey, K. V, and Jeppsson, U. (2016). 563 Catchment \& sewer network simulation model to benchmark control strategies within urban $564 \quad$ wastewater systems. Environmental Modelling and Software, 78, 16-30.

565 Sengeløv, G., Halling-Sørensen, B., Aarestrup, F. (2003). Susceptibility of Escherichia coli 566 and Enterococcus faecium isolated from pigs and broiler chickens to tetracycline degra567 dation products and distribution of tetracycline resistance determinants in E. coli from food 568 animals. Vet. Microbiol. 95, 91-101.

569 Snip, L.J.P., Flores-Alsina, X., Plósz, B.G., Jeppsson, U., Gernaey, K.V. (2014). Modelling the 570 occurrence, transport and fate of pharmaceuticals in wastewater systems. Environmental $571 \quad$ Modelling and Software 62, 112-127.

572 Snip, L.J.P, Flores-Alsina, X., Aymerich, I., Rodríguez-Mozaz, S., Barceló, D., Plósz, B.G., 573 Corominas, Ll., Rodriguez-Roda, I., Jeppsson, U., Gernaey, K.V. (2016). Generation of 574 synthetic influent data to perform (micro)pollutant wastewater treatment modelling studies. 575 Science of the Total Environment, 569-570, 278-290.

576 Thai, P.K., Jiang, G., Gernjak, W., Yuan, Z., Lai, F.Y., Mueller, J.F. (2014). Effects of sewer 577 conditions on the degradation of selected illicit drug residues in wastewater. Water $578 \quad$ Research, 48, 538-547. 
579 Vezzaro, L., Benedetti, L., Gevaert, V., De Keyser, W., Verdonck, F., De Baets, B., Nopens, 580 I., Cloutier, F., Vanrolleghem, P.A., Mikkelsen, P.S., (2014). A model library for dynamic 581 transport and fate of micropollutants in integrated urban waste-water and stormwater $582 \quad$ systems. Environmental Modelling and Software, 53, 98-11.

583 Wolfs, V., Villazon, M.F., Willems, P. (2013) Development of a semi-automated model 584 identification and calibration tool for conceptual modelling of sewer systems. Water Science $585 \quad$ and Technology, 68, 167-175.

586 Zoppou, C. (2001). Review of urban storm water models. Environmental Modelling and Software, 587 16 (3), 195-231. 


\section{Modelling micropollutant fate in sewer systems - A new}

\section{systematic approach to support conceptual model construction based on in-sewer hydraulic retention time}

Riccardo Delli Compagni ${ }^{1}$, Fabio Polesel ${ }^{2,3}$, Kerstin J.F. von Borries ${ }^{2}$, Zhen Zhang $^{2}$, Andrea Turolla $^{1}$, Manuela Antonelli ${ }^{*}$ and Luca Vezzaro ${ }^{2 *}$

${ }^{1}$ Department of Civil and Environment Engineering (DICA), Politecnico di Milano, Piazza Leonardo da Vinci 32, 20129 Milan, Italy

${ }^{2}$ DTU Environment, Technical University of Denmark, Bygningstorvet, Building 115, 2800 Kongens Lyngby, Denmark 3DHI A/S, Agern Allé, 2970 Hørsholm, Denmark.

\section{SUPPLEMENTARY MATERIAL}

Number of pages: 5 


\section{Materials and methods}

\section{Identification of sub-catchments}

The Dijkstra's algorithm (taking its name from the inventor, Edsger W. Dijkstra), is used to find the shortest path between nodes in a graph or a network by solving an optimization problem (Cormen, 2001). In the current study, we used the algorithm to identify the shortest in-sewer path from each discharge point to the wastewater treatment plant.

\section{Building the conceptual model}

Table S1 describes the calculations utilized to define the structure and the parameters of each sub-catchment. These values are utilized in the different blocks from the IUWS_MP library.

Table S1: Conceptual model parameters for each sub-catchment; n.d. stands for not defined.

\begin{tabular}{|c|c|c|c|c|c|c|}
\hline & $\begin{array}{c}\text { Population } \\
\text { density } \\
\rho\left[\text { inh } \mathrm{km}^{-2}\right]\end{array}$ & $\begin{array}{c}\text { Wastewater } \\
\text { production } \\
W W P\left[\mathrm{~m}^{3} \mathrm{inh}^{-1} \mathrm{~s}^{-1}\right]\end{array}$ & $\begin{array}{l}\text { Infiltration } \\
\text { flow rate } \\
\text { Ifr }\left[\mathrm{m}^{3} \mathrm{~s}^{-1}\right. \\
\left.\mathrm{km}^{-2}\right]\end{array}$ & $\begin{array}{c}\text { Area } \\
A_{i}\left[\mathrm{~km}^{2}\right]\end{array}$ & $\begin{array}{c}\text { Hourly } \\
\text { peak } \\
\text { factors } \\
\text { for WW } \\
\text { release } \\
P F[-]\end{array}$ & $\begin{array}{l}\text { Number of in- } \\
\text { series CSTR [-] }\end{array}$ \\
\hline Source & $=\frac{1.250 .000^{a}}{69^{b}}$ & $=\frac{0.22^{c} *\left(1-\alpha^{d}\right)}{C f^{e}}$ & $=\frac{Q_{\text {inf, }, t o t}{ }^{f}}{69^{b}}$ & $=\frac{Q_{P W, i}^{g}\left(1-\alpha^{d}\right)}{\rho * W W P}$ & pattern $^{h}$ & n.d. \\
\hline Sewer & n.d. & n.d. & n.d. & n.d. & n.d. & $\begin{array}{l}\begin{array}{l}\text { Iteratively adjusted } \\
\text { to minimise }\end{array} \\
\frac{\left|H R T_{i}^{f}-H R T_{\text {simulated }}\right|^{l}}{H R T_{\text {simulated }}}\end{array}$ \\
\hline \multicolumn{7}{|c|}{$\mathrm{b}$ Total urban area in $\mathrm{km}^{2}$} \\
\hline \multicolumn{7}{|c|}{${ }^{\mathrm{c}}$ Average potable water consumption in the study area in $\mathrm{m}^{3} \mathrm{inh}^{-1} \mathrm{~d}^{-1}$ (ISTAT, 2018) } \\
\hline \multicolumn{7}{|c|}{${ }^{\mathrm{e}}$ Conversion factor equals to $86400 \mathrm{~s} \mathrm{~d}^{-1}$} \\
\hline \multicolumn{7}{|c|}{${ }^{\mathrm{f}}$ Estimated from section 2.2 .2 ; see equation $1-2$} \\
\hline \multicolumn{7}{|c|}{$\begin{array}{l}\text { h Normalized daily potable water consumption pattern for workdays (Monday to Friday) reported by Candelieri } \\
\text { and Archetti (2014) }\end{array}$} \\
\hline
\end{tabular}


Equation S1 describes how the dry weather flow for each $\mathrm{i}^{\text {th }}$ catchment (sum of wastewater flow $Q_{w w, i}$ and infiltration flow $\left.\mathrm{Q}_{\text {inf,i }}\right)$ is calculated by the WEST model.

$$
Q_{d w f, i}=Q_{w w, i}+Q_{\text {inf }, i}=\rho * W W P * A_{i} * P F+I f r * A_{i}
$$

where $\rho\left[\mathrm{inh} \mathrm{km}^{-2}\right]$ is the population density, $W W P\left[\mathrm{~m}^{3} \mathrm{inh}^{-1} \mathrm{~s}^{-1}\right]$ the per capita wastewater production, $A_{i}\left[\mathrm{~km}^{2}\right]$ the area of the $\mathrm{i}^{\text {th }}$ sub-catchment and, $P F$ the peak factors to introduce flow temporal variability; $\operatorname{Ifr}\left[\mathrm{m}^{3} \mathrm{~s}^{-1} \mathrm{~km}^{-2}\right]$ is the groundwater infiltration rate.

Table S2 indicates the number of tanks (in the IUWS_MP library indicated as pipes) and the corresponding length after model calibration. The relative deviation was calculated according to the equation reported in Table S1. The volume of each pipe, obtained as product of the surface and length of the pipe, was initially fixed $\left(\sim 1750 \mathrm{~m}^{3}\right)$ and slightly tuned for minor adjustments once the optimal number of CSTRs was found.

Table S2. Model parameters and performance indicator for each sub-catchment.

\begin{tabular}{cccc}
\hline Sub-catchment & $\begin{array}{c}\text { Number } \\
\text { of tanks }(-)\end{array}$ & $\begin{array}{c}\text { Length of } \\
\text { each pipe }(\mathrm{m})\end{array}$ & $\begin{array}{c}\text { Relative } \\
\text { deviation }(\%)\end{array}$ \\
\hline A & 5 & 600 & 3.1 \\
B & 8 & 600 & 5.3 \\
C & 9 & 650 & 0.2 \\
D & 10 & 500 & 2.5 \\
E & 12 & 650 & 2.5 \\
F & 12 & 475 & 0.8 \\
\hline
\end{tabular}


Scenario 2: Effect of complex retransformation pathways.

Table S3 shows the parameters combinations (12 in total) that were tested in scenario 2. The third column indicates the proportion between the release concentration of the parent micropollutant and its retransformable fractions.

Table S3: parameter combination for each simulation for scenario 2.

\begin{tabular}{cccc}
\hline $\begin{array}{c}\text { Half-life } \\
\text { biodegradation }\end{array}$ & $\begin{array}{c}\text { Half-life } \\
\text { retransformation }\end{array}$ & $\begin{array}{c}\text { Retransformable } \\
\text { fraction/parent }\end{array}$ & $\begin{array}{c}\text { Simulation } \\
\text { number }\end{array}$ \\
\hline $2.5 \mathrm{~h}$ & $20 \mathrm{~min}$ & 1 & 1 \\
& & 10 & 2 \\
$2.5 \mathrm{~h}$ & $2.5 \mathrm{~h}$ & 1 & 3 \\
& & 10 & 4 \\
$2.5 \mathrm{~h}$ & $40 \mathrm{~h}$ & 1 & 5 \\
& & 10 & 6 \\
$40 \mathrm{~h}$ & $20 \mathrm{~min}$ & 1 & 7 \\
& & 10 & 8 \\
$40 \mathrm{~h}$ & $2.5 \mathrm{~h}$ & 1 & 9 \\
& & 10 & 10 \\
$40 \mathrm{~h}$ & $40 \mathrm{~h}$ & 1 & 11 \\
\hline
\end{tabular}

\section{Results and discussion}

Scenario analysis

Scenario 1-Effect of degradation

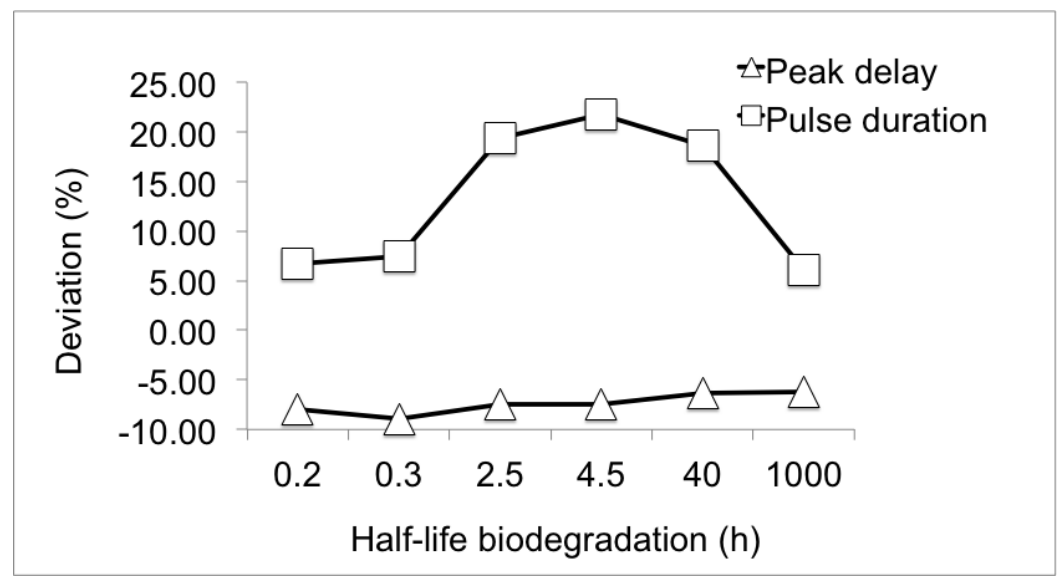


Figure S1. Deviation for the peak delay and pulse duration between the multi-catchment model and the single-catchment model for different biodegradable half-lives.

\section{Scenario 2 - Effect of complex transformation pathways}

Table S4. Comparison between predicted and measured in-sewer removal efficiencies for MPs. Characteristics of investigated sewers are provided for literature studies.

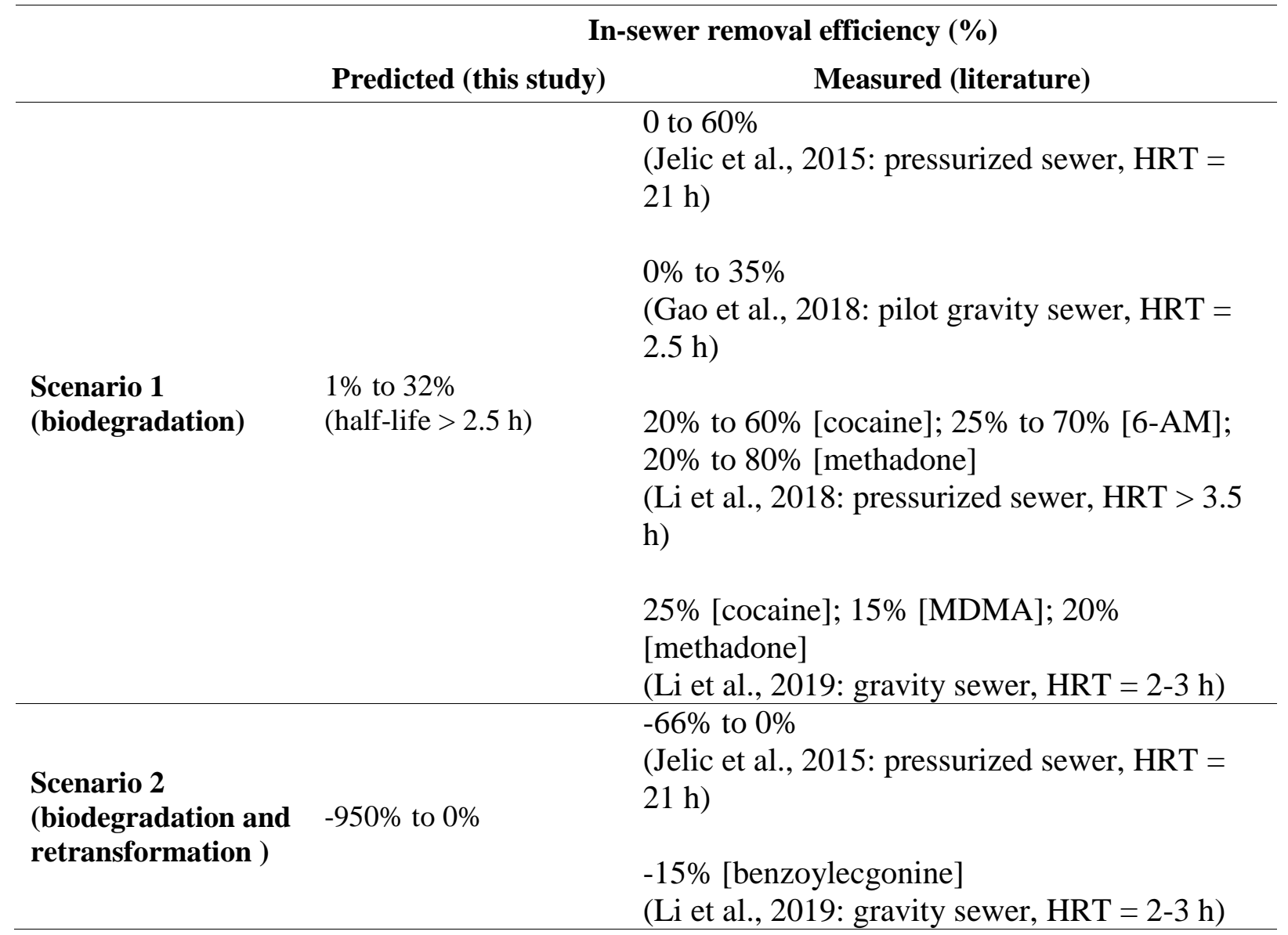

Scenario 3 - Effect of point source location

Table S5. Simulated removal efficiencies by the multi-catchment model and the single-catchment model for different point source locations and biodegradable half-lives.

\begin{tabular}{cccc}
\hline Half-life & Single-catchment & Sub-catchment F & Sub-catchment A \\
\hline $12 \mathrm{~min}$ & 99 & 99 & 88 \\
$2.5 \mathrm{~h}$ & 37 & 46 & 19 \\
$40 \mathrm{~h}$ & 4 & 5 & 2 \\
\hline
\end{tabular}




\section{References}

Butler, D. and Davies J.W. (2004). Urban Drainage (Second edition). CRC Press, London, UK.

Candelieri, A. and Archetti, F. (2014). Identify typical urban water demand pattern for a reliable short-term forecasting - The icewater project approach. Procedia Engineering, $89,1004-1012$.

Cormen, T. H., Leiserson, C. E., Rivest, R. L., Stein, C. (2001). Dijkstra's algorithm. Introduction to Algorithms (Second ed.). MIT Press and McGraw-Hill, 595-601.

Gao, J., Li, J., Jiang, G., Shypanski, A.H., Nieradzik, L.M., Yuan, Z., Mueller, J.F., Ort, C., Thai, P.K. (2019). Systematic evaluation of biomarker stability in pilot scale sewer pipes. Water Res. 151, 447-455.

Italian National Institute of Statistics (ISTAT), 1926. Open data. http://dati.istat.it/Index.aspx?DataSetCode=DCCV_INDACQDOM\# (Accessed 15 April 2018).

Jelic, A., Rodriguez-Mozaz, S., Barceló, D., Gutierrez, O. (2015). Impact of in-sewer transformation on 43 pharmaceuticals in a pressurized sewer under anaerobic conditions. Water Res. 68, 98-108.

Li, J., Gao, J., Thai, P.K., Sun., X., Mueller, J.F. Yuan, Z., Jiang, G. (2018). Stability of illicit drugs as biomarkers in sewers: From lab to reality. Environ. Sci. Technol. 52, $1561-1570$.

Li, J., Gao, J., Thai, P.K., Shypanski, A., Nieradzik, L., Mueller, J.F. Yuan, Z., Jiang, G. (2019). Experimental investigation and modeling of the transformation of illicit drugs in a pilot-scale sewer system. Environ. Sci. Technol., accepted, doi: 10.1021/acs.est.8b06169. 